\title{
TTR
}

Traduction, terminologie, re?daction

\section{Lawrence Venuti. The Translator's Invisibility. A History of Translation. London and New York, Routledge, coll. "Translation Studies ", 1995, 353 pages.}

\section{Corinne Durin}

Volume 8, numéro 2, 2e semestre 1995

Technolectes et dictionnaires

URI : https://id.erudit.org/iderudit/037229ar

DOI : https://doi.org/10.7202/037229ar

Aller au sommaire du numéro

Éditeur(s)

Association canadienne de traductologie

ISSN

0835-8443 (imprimé)

1708-2188 (numérique)

Découvrir la revue

Citer ce compte rendu

Durin, C. (1995). Compte rendu de [Lawrence Venuti. The Translator's Invisibility. A History of Translation. London and New York, Routledge, coll. " Translation Studies », 1995, 353 pages.] TTR, 8(2), 283-286.

https://doi.org/10.7202/037229ar

Tous droits réservés ( $\mathrm{TTR}$ : traduction, terminologie, rédaction — Les auteurs, Ce document est protégé par la loi sur le droit d’auteur. L’utilisation des 1995 services d’Érudit (y compris la reproduction) est assujettie à sa politique d'utilisation que vous pouvez consulter en ligne.

https://apropos.erudit.org/fr/usagers/politique-dutilisation/ 


\section{Lawrence Venuti. The Translator's Invisibility. A History of Translation. London and New York, Routledge, coll. «Translation Studies», 1995, 353 pages.}

L'invisibilité des traducteurs et des traductrices, voilà ce que Lawrence Venuti entend combattre dans son magistral ouvrage, The Translator's Invisibility. A History of Translation, qui marque l'aboutissement d'une dizaine d'années de recherches. S'y trouvent réunis sous une forme remaniée bon nombre des articles de l'auteur portant sur divers cas de figure de la traduction dans l'espace occidental.

Notons que l'histoire dont il est question n'affiche aucune prétention à l'objectivité, pas plus qu'à l'exhaustivité. Tout comme la lecture des traductions choisies, la lecture historique qu'effectue l'auteur relève d'une prise de position explicite et résolument orientée par des enjeux se conjuguant au présent. Aussi une lecture «symptomatique» des textes traduits se donne-t-elle pour tâche d'en révéler le soubassement idéologique (et l'impossible transparence) par l'examen des ruptures discursives qui attestent le faire traducteur et renvoient fatalement à leur ancrage socio-historique. De même, une lecture généalogique de l'histoire porte une attention particulière aux pratiques traductives «déviantes», dès lors susceptibles de servir de modèles aux traducteurs contemporains.

C'est qu'en effet l'auteur dénonce avec virulence, dans la foulée d'Antoine Berman, le régime du traduire qui prévaut dans l'espace angloaméricain, régime fondé sur les notions de transparence et de lisibilité, opérant à la fois sur la production et la réception des textes traduits. Les conséquences d'un tel régime sont loin d'être négligeables. D'une part, l'impératif dictant l'effacement des traces de la réénonciation n'est pas étranger, on le sait, à la marginalisation des activités de traduction et au piètre statut économique, juridique et symbolique qui est le lot des traducteurs. D'autre part, l'adoption du critère de la lisibilité («fluency») revient le plus souvent à l'annexion des textes étrangers, à la quête du Même au prix de l'Autre, et consoliderait 
simultanément les rapports de domination qu'entretiennent les puissancesangloaméricaines avec les cultures qu'elles traduisent.

On le voit, l'auteur n'hésite pas à accorder à la traduction, qu'il assimile à une pratique politique et culturelle dont la nature est foncièrement violente, un rôle de premier pian, tant au sein de la société d'accueil que dans la politique étrangère qu'elle poursuit. Le constat du potentiel qu'aurait la traduction de renforcer, ou éventuellement de déstabiliser, canons littéraires, paradigmes conceptuels et images des cultures étrangères, explique le caractère polémique de l'ouvrage. Si ce dernier s'adresse à un public pluriel traductologues, critiques littéraires - $c$ 'est donc avant tout aux traducteurs et aux lecteurs qu'il se destine: «The ultimate aim of the book is to force translators and their readers to reflect on the ethnocentric violence of translation and hence to write and read translated texts in ways that seek to recognize the linguistic and cultural difference of foreign texts» (p. 41). C'est dire que les traducteurs, loin d'être les simples relais du discours social dominant, ont le pouvoir de faire de leur travail une pratique lucide, engagée et transformatrice, ce que le critique appelle de ses vœux. La mise au jour du socle idéologique de certaines traductions se donnant pour transparentes, leur dénaturalisation, tout comme la reconstitution d'une tradition marginale et contestataire du traduire - «la face cachée, le continent noir de l'histoire de la traduction occidentale", selon les termes de Berman ${ }^{2}$ - contrent de manière décisive l'invisibilité des sujets traduisants et font de l'ouvrage de Venuti une étape essentielle dans l'établissement de nouveaux modes d'appréhension des textes étrangers.

On trouvera, à la suite de l'exposé de la problématique et de la démarche adoptée, cinq chapitres qui analysent avec finesse diverses pratiques de la traduction ayant eu cours du XVII ${ }^{e}$ siècle à nos jours, en Angleterre, en Allemagne, en Italie et aux États-Unis. Les traductions régies par le paradigme de la transparence se voient réinscrites dans l'histoire, les enjeux qui les soustendent démasqués, à commencer par la traduction de Sir John Denham, publiée en Angleterre en 1656, qui relevait d'une tentative de réaffirmation du prestige de l'aristocratie royaliste, et qui marqua la résurgence d'un mode annexioniste du traduire axé sur la lisibilité, préfigurant la formulation canonique que lui donnerait Alexander Tytler en 1791 dans son Essay on the Principles of Translation. Il ne s'agit là que d'un exemple parmi d'autres, plus contemporains, d'une traduction qui, sous couvert de transparence, annexe

2. Antoine Berman, «la Traduction et la lettre, ou l'auberge du lointain», les Tours de Babel (Mauvezin, Trans-Europ-Repress, 1985) p. 37. 
l'Étranger du texte de départ dans l'intérêt d'une classe ou d'un groupe social donnés.

Il serait naïf de croire, toutefois, qu'une traduction accomplie selon des modalités différentes puisse davantage échapper aux discours du polysystème dont elle est issue et saisir de manière absolue l'Autre en tant qu'Autre. Comme le souligne à maintes reprises l'auteur, traduire signifie poser un acte d'appropriation, l'Étranger ne pouvant être appréhendé qu'en fonction du Propre. Pensons à l'éthique de la traduction prônée par les Romantiques allemands, qui servait les intérêts d'une élite cherchant à asseoir l'identité nationale et s'opposait à la domination de la France dans la culture de la cour. Ou encore au projet d'Iginio Ugo Tarchetti, écrivain italien du XIX ${ }^{\mathrm{e}}$ siècle, qui tout en important la critique «féministe» d'une Mary Wollestonecraft en effaçait la maternité - la traduction se faisant passer pour un original - et en déplaçait les enjeux en fonction de sa société, afin de remettre en question le courant réaliste qui y prévalait.

On peut s'interroger, dès lors, sur la distinction qui subsiste entre traduction transparente et non transparente, puisque toutes deux reviennent à une réécriture de l'œuvre reposant sur des critères spécifiques à l'horizon d'accueil. Mais tandis que la première se refuse à s'écarter des valeurs et normes établies, réduisant l'original jusqu'à ce qu'il s'y conforme, la seconde les conteste au contraire, en puisant dans des discours marginalisés aptes à manifester l'Étranger du texte de départ. C'est bien sûr dans la seconde que réside le pouvoir de la traduction et c'est elle que valorise Venuti, dans la mesure où elle permet une déstabilisation des normes et des valeurs du Propre.

L'auteur encourage donc les traducteurs à adopter des stratégies de sélection et de traduction allant à l'encontre des discours dominants, à tel point que l'on se demande parfois si la visée éthique du traduire proposée n'est pas davantage orientée par un désir de subversion des codes de la société d'accueil que par un mouvement d'ouverture sur l'Autre. D'ailleurs, l'acception très large que reçoit le concept de travail sur la lettre va dans le même sens et, dans cette optique, il n'est pas étonnant qu'il soit rarement question du dégagement (même médiatisé) de la Vérité de l'œuvre, de son projet, de son organicité.

Lorsqu'on sait la réception qui fut réservée aux pratiques marginales ou expérimentales telles celles de Pound, de Blackburn, des Zukofsky et de Venuti lui-même, on doit s'interroger sur la portée réelle que peut avoir une traduction dans nos sociétés et sur le caractère utopique de l'injonction faite ici aux sujets traduisants. En conclusion, Venuti reconnait que certaines des pratiques exposées restent irrecevables à l'heure actuelle et que les traducteurs auront nécessairement à faire des compromis, sans pour autant abandonner 
l'espoir que la traduction puisse être porteuse de changement: «the suspicion [toward translation] I am encouraging here assumes a utopian faith in the power of translation to make a difference, not only at home, in the emergence of new cultural forms, but also abroad, in the emergence of new cultural relations" ( $p$. 313).

Corinne DURIN

Université McGill 